\title{
Guidelines for Counsellors Working with People of African Ancestry in a Sport Context
}

\section{Lourens Human, Taunya Tinsley, Monja Muller \& Sipho Rutsate}

To cite this article: Lourens Human, Taunya Tinsley, Monja Muller \& Sipho Rutsate (2009)

Guidelines for Counsellors Working with People of African Ancestry in a Sport Context, Journal of Psychology in Africa, 19:4, 471-482, DOI: 10.1080/14330237.2009.10820318

To link to this article: https://doi.org/10.1080/14330237.2009.10820318

曲 Published online: 01 May 2014.

Submit your article to this journal

Џ Article views: 41 


\title{
Guidelines for Counsellors Working with People of African Ancestry in a Sport Context
}

\author{
Lourens Human \\ University of Pretoria, South Africa \\ Taunya Tinsley \\ California University of Pennsylvania, PA \\ Monja Muller \\ University of Pretoria, South Africa
}

\author{
Sipho Rutsate \\ National University of Science and Technology, Zimbabwe
}

Address correspondence to Dr. Lourens Human, Department of Psychology, University of Pretoria, Pretoria, 0001, South Africa. E-mail: lourens.human@up.ac.za.

The objective this article is to describe five practice guidelines for counsellors working with people of African ancestry in a sport context. The practice guidelines pertain to counsellor training, counsellor perspectives, counsellor services, counsellor ethics and counsellor research. These practice guidelines can assist counsellors working with people of African ancestry in a sport context to focus on both personal development through sport and performance enhancement in sport. This will enable athletes not just to view sport in terms of their win-lose record, but to also strive for excellence in sport by becoming better people. In becoming better people athletes can contribute to building up Africa and her people.

Keywords: counsellor, sport, African ancestry, developmental perspective, psychopathology, cognitive-behaviour perspective, multi-level classification system for sport psychology (MCS-SP), systemic narrative perspective

\section{Introduction}

People worldwide participate in sport on a recreational and/or professional level. Greenspan (in Lesyk, 2001, p.12) reflects on this phenomenon as follows:

It is dawn; the early morning fog has not yet lifted. Before the sun breaks the horizon hundreds of athletes throughout the world, begin their day as they have in the past, as they will continue to do in the future. This ritual is repeated everyday, on the beaches, the countryside, the mountains, gymnasiums, swimming pools and tracks. The already great and those who aspire to be, share the same dream, the pursuit of excellence.

Unfortunately, too often athletes view sport in terms of their win-loss record, and forget that sport is primarily about becoming a better person. As Lesyk ( Lesyk, 2001, p. 6) states:

Remember that you engage in sport because it enhances your life. You owe it to yourself and to those who care about you to do your best. You cannot do more. Win or lose you're still the same person and life goes on. It is your chosen commitment and struggle towards excellence that makes you a better person, not your win-loss record.

However, professionals (e.g., physicians, physiotherapists) have become increasingly involved in the sport context with the aim of enhancing personal development and performance of athletes. The focus of this article is on proposing practice guide- lines, specifically for counsellors ${ }^{1}$ delivering sports counselling and sport psychology services to athletes of African ancestry ${ }^{2}$ in a sport context. Five practice guidelines are discussed in this article. These are counsellor training, counselor perspectives, counsellor services, counsellor ethics and counsellor research.

\section{Guideline 1: Counsellor Training}

The first practice guideline pertaining to counsellors working with athletes is counsellor training. From the history of sports counselling and sport psychology it has become apparent that counsellor training is imperative and should precede counsellor practice.

\section{History of Sports Counselling}

During the latter half of the previous century, the area of sports counselling received much attention in the literature. However, the focus in the literature was mainly on the counselling needs of athletes in American and European contexts. One of the problems of the history of sports counselling outside the context of Africa, as noted by Cole and Tinsley (2009), is that the counselling of athletes, as well as counselling models and initiatives that have identified the needs of athletes, have preceded the development of preparation programs and as yet are not fully integrated into counsellor education programs.

To help address this problem, competencies for athletic counsellors were developed in the visionary model Counsellors 
of Tomorrow by the Association for Counsellor Education and Supervision two decades ago in the United States of America (USA)(Nejedlo, Arrendondo \& Benjamin, 1985). Nejedlo et al. (1985, p. 9) defined athletic counselling (i.e., sports counselling) as "a process which attempts to assist individuals in maximizing their personal, academic, and athletic potential. This [athletic counselling] is accomplished through a proactive, growth-oriented approach that incorporates the principles of counselling, psychology, and human development". During this decade Ward, Sandstedt, Cox and Beck (2005) developed athlete-counselling competencies for psychologists working in the USA, by focussing on the aspects of beliefs, knowledge and skill competencies.

There seems to be a lack of research on sports counselling in Africa. Tinsley and Levers (2007, p. 23) did a study on "the development of psycho-social skills, self-determination, and resilience among Botswana youth through sports counselling". In this study the researchers also provided research evidence through an extensive review of literature that connects the history of sport in Africa, professional counselling, sports counselling, multicultural counselling competencies, support services for athletes, and the international athlete population with the hope that people in the helping professions (e.g., counsellors, psychologists, social workers, educators) will be better prepared to respond to the developmental needs of athletes and provide effective and quality counselling services.

In South Africa (SA) the Department of Psychology at the University of Pretoria (UP) offers a MA (Counselling Psychology) program, which is accredited with the Health Professions Council of South Africa (HPCSA), in which students are taught sports counselling. The sports counselling training focuses on performance termination, impairment and dysfunction, as seen by the Multi-Level Classification System for Sport Psychology (MCS-SP)(Gardner \& Moore, 2004).

It seems from the history of sports counselling that the practice guideline of training programs for counsellors who work with athletes is important, necessitates the establishment of training competencies and should precede counsellor practice.

\section{History of Sport Psychology}

The history of sport psychology outside the continent of Africa seems to have a prominent place in sport psychology literature. One example is in the USA where Norman Triplett linked sport and psychology in 1889 with one another (Davis, Huss \& Becker, 1995). The Triplett era (1885-1935) was followed by Griffith era (1920-1940). Coleman Griffith is regarded internationally as the father of sport psychology, as he dedicated much of his career to sport and sport psychology (Gould \& Pick, 1995). As from the 1950's to the 1980's sport psychology grew tremendously with the expansion of sport psychology literature, the emergence of sport psychology programs, the establishment of sport psychology organisations, such as the International Society of Sport Psychology (ISSP)(1965), the North American Society for the Psychology of Sport and Physical Activity (NASPSPA)(1967) and the Association for the Advancement for Applied Sport Psychology (AAASP)(1985). Furthermore, numerous sport psychology journals also emerged like the International Journal of Sport Psychology (IJSP)(1970), the Journal of Sport and Exercise Psychology (JSEP)(1988), The Sport Psychologist (TSP)(1987) and the Journal of Applied Sport Psychology (JASP)(1989)(Brewer \& Van Raalte, 2002).

Another example of the prominence of sport psychology outside Africa is the history of sport psychology in Australia.
Sport psychology is a young discipline in Australia and has a very brief history. During the 1980's the Australian Institute of Sport (AIS) and the South Australian Sport of Institute (SASI) were established; AIS in 1982 and SASI in 1983 (Morris, 1995). There were very few psychology departments at universities that had staff or courses in sport psychology, as sport psychologists and sport psychology were mainly situated within physical education departments, for example at the University of Queensland and the University of Western Australia (Abernethy, Bond, Glencross, Grove \& Salmela, 1992). In the 1990s there were three sport psychology interest groups functioning in Australia. They were the Australian Applied Sport Psychology Association (AASPA), the Sport Psychology Association of Australia and New Zealand (SPAANZ) and Australian Society Sport Psychology Interest Network (AUSPIN). In 1990 AUSPIN presented a symposium at the annual conference of the Australian Psychological Society (APS), which was also attended by members of AASPA and SPAANZ. At this symposium all three sport psychology interest groups formed one steering committee that in May 1991, applied to the Committee of the Division of Professional Affairs of the APS for professional board status. The inaugural meeting of the Board of Sport Psychologists was held in November 1991 at the First Asian South Pacific Association of Sport Psychology Congress in Melbourne. At this meeting a National Executive Committee was elected, which was re-elected in 1992 at the Annual General Meeting of the APS in Armidale and once again re-elected in 1993 at the Annual General Meeting of the APS on the Gold Coast. The Board of Sport Psychologists has the tasks of setting training standards, monitoring careers in sport psychology, establishing and maintaining professional standards, as well as promoting research in the field of sport psychology. It is important to note that after the establishment of the Board of Sport Psychologists within the APS, Curtin University of Technology and Monash University in 1992, as well as the University of Southern Queensland and Victoria University in 1994, started running sport psychology masters programs with research and applied focuses (Morris, 1995).

However, it appears that the history of sport psychology in Africa has a very vague face. In South Africa, Dr. Danie Craven presented the first course in sport psychology at Stellenbosch University (SU) in the 1960s (Potgieter, 1997). Currently the Department of Sport Science in the Faculty of Education at SU offers a PhD (Sport Psychology) (Stellenbosch University [SUN], 2002a, 2002b). Furthermore, the Department of Psychology at the UP offers a MA (Counselling Psychology) program, which is accredited with the HPCSA, in which students are taught sport psychology. The sport psychology training focuses on performance development as seen by the MCS-SP (Gardner \& Moore, 2004).

It seems that the history of sport psychology not only emphasizes the practice guideline of counsellor training and competencies, but also the importance of establishing organisations (e.g., ISSP, NASPSPA, AASP) and journals (e.g., IJSP, JSEP, TSP, JASP) to stimulate the growth of sport psychology.

\section{Guideline 2: Counsellor Perspectives}

The second practice guideline for counsellors working with athletes is multiple counsellor perspectives. Four perspectives that can be employed by counsellors working with athletes are portrayed, including the developmental, the psychopathology, cognitive-behaviour, and the systemic-narrative perspectives. It is important to note that these are not the only perspectives that can be used by counsellors when working with athletes, but can 
form the basis from which counsellors can work. Furthermore, these perspectives should not be seen as mutually exclusive, but rather as complimenting one another.

In other words these perspectives can metaphorically be seen as team members of a sport team. On the one hand these team members are open to accommodating new team members into the team which can enhance the functioning and performance of the team, while on the other hand each team member uniquely plays a very important role within the team and needs the other team members to also enhance the functioning and performance of the team.

\section{Developmental Perspective}

The focus of the developmental perspective is to understand athletes within their various developmental phases. The reason is that athletes of different ages have different needs, which need to be addressed differently. For example, working with an athlete who is 10 years of age differs from working with an athlete who is 17 years of age. The term "development" refers to the normative changes athletes go through as they move from one developmental phase to the next developmenta phase. It is important to note that besides normative changes, athletes can also experience non-normative changes in their lives, such as a sport injury that temporarily or permanently changes the sport career of athletes (Pillari, 1988).

There are various developmental perspectives that counsellors can use when working with athletes. Although many of the traditional developmental perspectives did not originate within a sport context, they can be employed by counsellors working with athletes. For example, the developmental perspective of Erik Erikson can be used to understand the psycho-social development of athletes; the developmental perspective of Jean Piaget focuses on cognitive development and the developmental perspective of Lawrence Kohlberg focuses on moral development (Meyer \& Van Ede, 1994).

The developmental perspective also underlies Long-Term Athlete Development (LTAD) programs, such as the Canadian Sport for Life program. The underlying developmental principle of this LTAD-program is that athletes should be developed in their chosen sport over a long period of time on a physical, cognitive, emotional and behaviour level. This approach to developing athletes counters the fast tracking of athletes which is found in the sport context, and which is often to the detriment of athletes. Although chronological age plays a role in this LTAD-program, developmental age is also used as a guideline for athlete development. This LTAD-program consists of seven stages. The first three stages (Stage 1: Active Start; Stage 2: Fundamentals; Stage 3: Learning to Train) of this LTAD-program encourage physical literacy and sport participation. The next three stages (Stage 4: Training to Train; Stage 5: Training to Compete; Stage 6: Training to Win) of this LTAD-program focuses on excellence in sport. The last stage (Stage 7: Active for Life) in this LTAD-program emphasizes that people be active for life (Long-Term Athlete Development [LTAD], 2006). Counsellors working with athletes can use the LTAD-program as a framework in which they can deliver their services to athletes, as this allows counsellors to view athletes in the different stages of the LTAD-program.

\section{Psychopathology Perspective}

The word "psychopathology", also known as abnormal behaviour or mental disorder, is derived from two words, namely "psyche" and "pathology". The word psyche refers to mind while the word pathology denotes disease. Therefore, the word psychopathology means diseases of the mind (Preller,1989). Psychopathology is defined as a "psychological dysfunction associated with distress or impairment in functioning that is not a typical or culturally expected response" (Barlow \& Durand, 1995). There are various psychopathology perspectives which will briefly be discussed briefly (Theron \& Louw, 1989).

Firstly, there is the subjective perspective, which states that a person evaluates another person's behaviour in relation to his/her own behaviour and if this behaviour deviates from that person's behaviour, then this behaviour is seen as abnormal behaviour. For example, a coach who was a previous national soccer player judges the soccer performance of a group of primary school pupils in relation to his performance as a national soccer player. Because these primary school pupils are not performing according to what the coach has determined to be an excellent performance, he labels them by stating that there is something wrong with these primary school soccer players.

Secondly, there is the idealistic perspective, which postulates that there is an ideal person, for example Jesus Christ, and people need to aspire to be like this ideal figure. If they do not live up to this image, then this is seen as abnormal behaviour. In a sport context this can be seen when, for example, adolescents participating in sport try to achieve the same performance levels as sporting heroes they admire. When the adolescents fail to achieve the performance levels of their heroes, these adolescents often see themselves as not good enough and therefore as abnormal.

Thirdly, there is the cultural perspective, which states that normal behaviour is what most people exhibit in a particular culture, while abnormal behaviour is seen as behaviour patterns that are only demonstrated by a few people within a certain culture. In the SA context, historically, certain kinds of sport are more prominent in certain cultures than in other cultures. For example, young white boys primarily participate in rugby and cricket, while for young white girls netball and hockey are prominent sports. Participating in these sports is seen as normal. A young white person who decides to participate in a sport (e.g., table tennis, snooker) other than rugby, cricket, netball or hockey, can often be characterized as abnormal within the white community.

Fourthly, there is the statistical perspective which views abnormal behaviour as that behaviour that deviates from the average behaviour that people exhibit. For example, in a university setting, $80 \%$ of the university students participate in team sports, like rugby, cricket, soccer, netball and hockey. Only $20 \%$ of the students participate in individual sports, like athletics, squash, boxing and karate. Statistically, it would be regarded abnormal not to participate in a team sport and to opt for an individual sport within the university context.

Lastly, there is the dysfunctional perspective, which focuses on whether a person's behaviour is harmful to him/herself and the environment, and if so, this behaviour is seen as abnormal behaviour. This perspective would most probably be related to adventure sports, such as technical cave diving, where the life of the technical cave diver is often in danger due to the adventurous and extreme nature of the sport. Many people regard athletes participating in adventure sports as abnormal due to the inherent danger the sport poses to the athlete's life.

Two prominent diagnostic systems can be used for identifying and diagnosing psychopathology, being the Diagnostic and Statistical Manual of Mental Disorders (DSM) and the International Classification of Diseases (ICD). The former diagnostic 
system has its home within the American Psychiatric Association (APA) and the fourth edition of the DSM-IV is currently in use (American Psychiatric Association [APA], 2007), while the latter stems from the World Health Organization (WHO) of which the $10^{\text {th }}$ revision, the ICD-10, is currently in use (World Health Organization [WHO], 2007). There are two common mistakes that can be made by counsellors working with athletes. On the one hand counsellors can hold the position that psychopathology does not form part of any athlete's life as they are highly functioning people, while on the other hand counsellors with a strong clinical and/or counselling psychology background often over diagnose psychopathology when athletes seek their assistance (Marchant \& Gibbs, 2004).

There seems to be a substantial overlap regarding psychopathology between athletes and non-athletes. Mahoney and Suinn (1986), as well as Sherman and Thompson (2001), saw the typical presenting problems amongst athletes as depression, anxiety, eating disorders, substance abuse, the obsession to win and the fear of failure, as well as relationship and motivational concerns. Sundgot-Borgen (1994) reports that 1,3\% of professional athletes met the DSM-IV criteria for anorexia and $8 \%$ for bulimia nervosa, Brown (1978) states 5\% - 15\% of American athletes suffer from psych-social problems, while Johnson, Powers and Dick (1999) indicate that $13 \%$ of college athletes showed clinically sig- nificant problems. May (1986) says that counselling with athletes is comparable to counselling with non-athletes although athletes preferred to consult a sports counsellor who has a sound knowledge of sport and respects the role that it plays in the lives of athletes. Morgan (1985) is of the opinion that although athletes tend to be psychologically healthier than people who do not participate in sport, by the time they seek assistance they exhibit severe psychopathology.

\section{Cognitive-Behaviour Perspective}

The cognitive-behaviour perspective is in essence individualistic in nature focussing on an athlete's cognitions, emotions and behaviour (Anderson, Van Raalte \& Brewer, 2001). It is rooted in two main beliefs, namely: (1) cognitions impact on emotions and behaviour and (2) behaviour impacts on cognitions and emotions (Wright, Basco \& Thase, 2006). The fundamental aspects of the cognitive-behaviour perspective are reflected in Figure 1.

Cognitions are personalised ideas that are activated by stimuli that result in emotional and behavioural responses (Corey, 2001). For example, when a soccer team scores a goal in the first minute of a game (stimuli), players in the apposing team might think (cognition) that the opposing team is very good, which may lead to anxiety (emotion) and subsequently

\section{Figure 1. Cognitive-behavior perspective}

Event

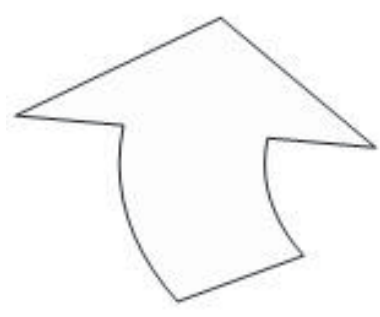

(3)

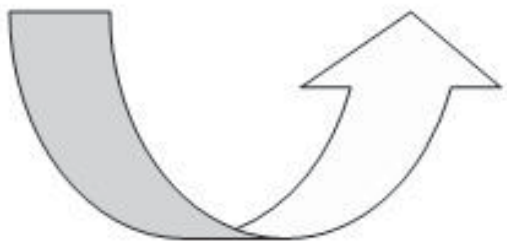

Behaviours

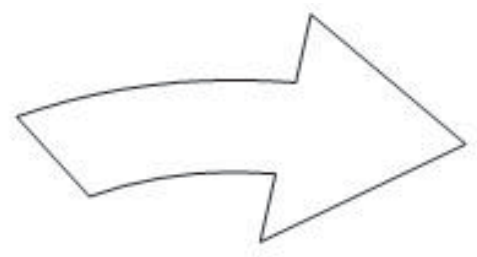

(1)

Cognitions

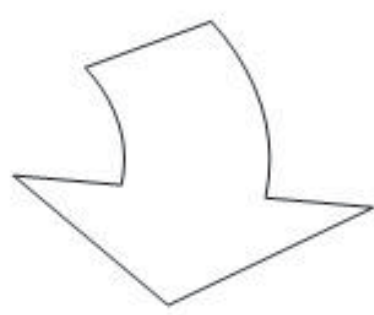

(2)

Emotions

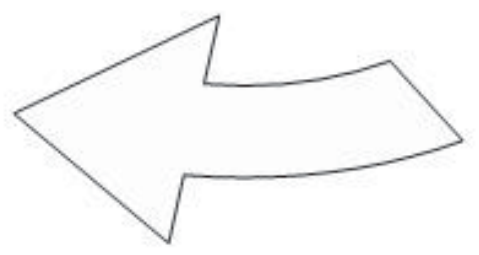

(Adapted from Wright et al., 2006) 
under performance (behaviour). Research shows that a high frequency of cognitions is present in people with various psychiatric conditions, like depression and anxiety. People often display cognitive errors in their cognitions. There are six main categories of cognitive errors that will be discussed in further detail. These are (Wright, et al., 2006):

Selective Abstraction. This is when athletes only focus on a certain section of vast information with the aim of substantiating a bias in their lives. For example, in the post-game sessions, the coach always gives positive and negative feedback to Mitchwe's netball team members. By focusing on negative aspects of the feedback, Mitchwe may not realize that she is a good netball player.

Arbitrary Inference. This is when athletes reach a conclusion about a specific issue, in the light of contradictory information and/or in the absence of information. For example, Mitchwe sustained an injury during a netball game. The coach asks her to go and see the medical team to assist in her recovery process. She makes an appointment with the medical team, but before this consultation, she concludes that she will never recover. With her consultation, the medical team informs her that the recovery process will take eight weeks, but despite this, she keeps on believing that she will never play netball again.

Magnification and Minimization. This is when athletes tend to exaggerate or minimize the significance of an event. For example, after eight weeks of intensive recovery of the injury that Mitchwe sustained during a netball game, the medical team gives the go ahead for her to practise netball and participate in games. In the first game she plays, Mitchwe plays exceptionally well, and when the coach congratulates her on this, she says it's not such a big deal. However, on the other hand Mitchwe's mother is telling all the spectators on the pavilion that based on Mitchwe's performance that day, she is surely going to be the netball player of the year.

Overgeneralization. This is when athletes reach a conclusion about one or two isolated events and they illogically transfer this conclusion to all events. For example, during a netbal game Mitchwe participated in, her opponent succeeded in intercepting the ball twice in the beginning of the game. Mitchwe started telling herself that her opponent was going to intercept all the balls during the netball game, and that she would therefore contribute to her team losing the game.

Personalisation. This is when athletes tend to relate external events to themselves without any basis, and excessive responsibility taken for negative events. For example, in one of the netball games Mitchwe participated in, her team lost against their opponents. Mitchwe really played her heart out and she was one of the star players during this game. However, she kept on telling herself that she did not do enough to help her team win that particular game, and that she was therefore responsible for her team losing that specific game.

Absolutistic Thinking. This is when athletes tend to see their world in one of two categories, being "bad" or "good", a "failure" or "success". For example, during Mitchwe's netball career she struggled with the concept that netball players can also learn about themselves even if they have lost the game or, although a netball team has won the game, they might not learn anything about themselves. The fact that learning is often paradoxical in sport was not acceptable to her as she saw winning as "good" and losing as "bad".

Therefore, the cognitive-behaviour perspective, which is primarily used for performance enhancement of athletes in a sport context, focuses on teaching athletes "effective ways of cognitively managing their performance with the expectation that these methods will lead to better performance" (Murphy, 1995, p. 6). It can help the counsellor identify the relationships between thoughts, emotions and behaviour of an athlete and to implement specific interventions based on cognitive-behaviour methods.

However, Tricket, Watts and Birman (1994) are of the opinion that diversity amongst athletes has challenged the foundations of sports counselling and sport psychology, which has caused a paradigmatic crisis. Sports counselling and sport psychology also need to adopt a position of understanding people in context, in the culture they live in and move away from solely understanding human behaviour that emphasizes internal cognitive processes and experimental designs.

\section{Systemic-Narrative Perspective}

The systemic-narrative perspective is predominantly used within the fields of clinical mental health counseling, clinical psychology, and/or counselling psychology (e.g., couples and family therapy), and allows counsellors to understand athletes in context, within their cultural settings. The fundamental aspects of the systemic-narrative perspective are reflected in the following diagram:

The systemic-narrative perspective has a contextual character implying that in any given context there are various interrelated systems. For the purpose of this chapter the focus will be on the personal system, the social system and the spiritual system. These interrelated systems are imbedded within specific cultures, which profoundly impact on the functioning of these systems through cultural narratives (White, 2000).

Firstly, there is the athlete's personal system, or otherwise stated, the athlete's relationship with "Self". This implies that any athlete lives in a relationship with him/herself as an individual person. This personal system is constituted on the one hand by an athlete being embodied, or otherwise stated, by an athlete's bodyliness (e.g., anatomy and physiology), as well as by an athlete's psychological make-up (e.g., cognitions, emotions and behaviour). It is important that counsellors working with athletes take note of this relationship and how it impacts on the athlete's participation and performance in the sport context.

Secondly, there is the athlete's social system, or otherwise stated the athlete's multitude of relationships with "Others". This multitude of relationships include having relationships with nuclear and/or extended family, with boyfriends and/or girlfriends, with fellow athletes, be it in the form of one-one relationships or with the sport team as a whole, with the coaching staff (e.g., head coach \& assistant coach(es)), as well as with the multidisciplinary team (e.g., medical doctor, physiotherapist, dietician and psychologist). It is important that counsellors working with athletes take cognisance of these relationships and how they influence an athlete's participation and performance in the sport context.

Thirdly, there is the athlete's spiritual system, or otherwise the athlete's potential relationship with a "Deity". It is important to mention that on the one hand not all athletes have a relationship with a Deity, while on the other hand the relationship with a Deity can be described as a kaleidoscope, as the term Deity is used in a very broad sense in this article so as to accommodate the kaleidoscope of Deities. However, what is of the utmost importance is that counsellors working with athletes will firstly be aware of their own position pertaining to the functioning or non-functioning of a spiritual system in their lives and secondly, that they will respect the kaleidoscope of Deities that form part 
Figure 2. Systemic-narrative perspective

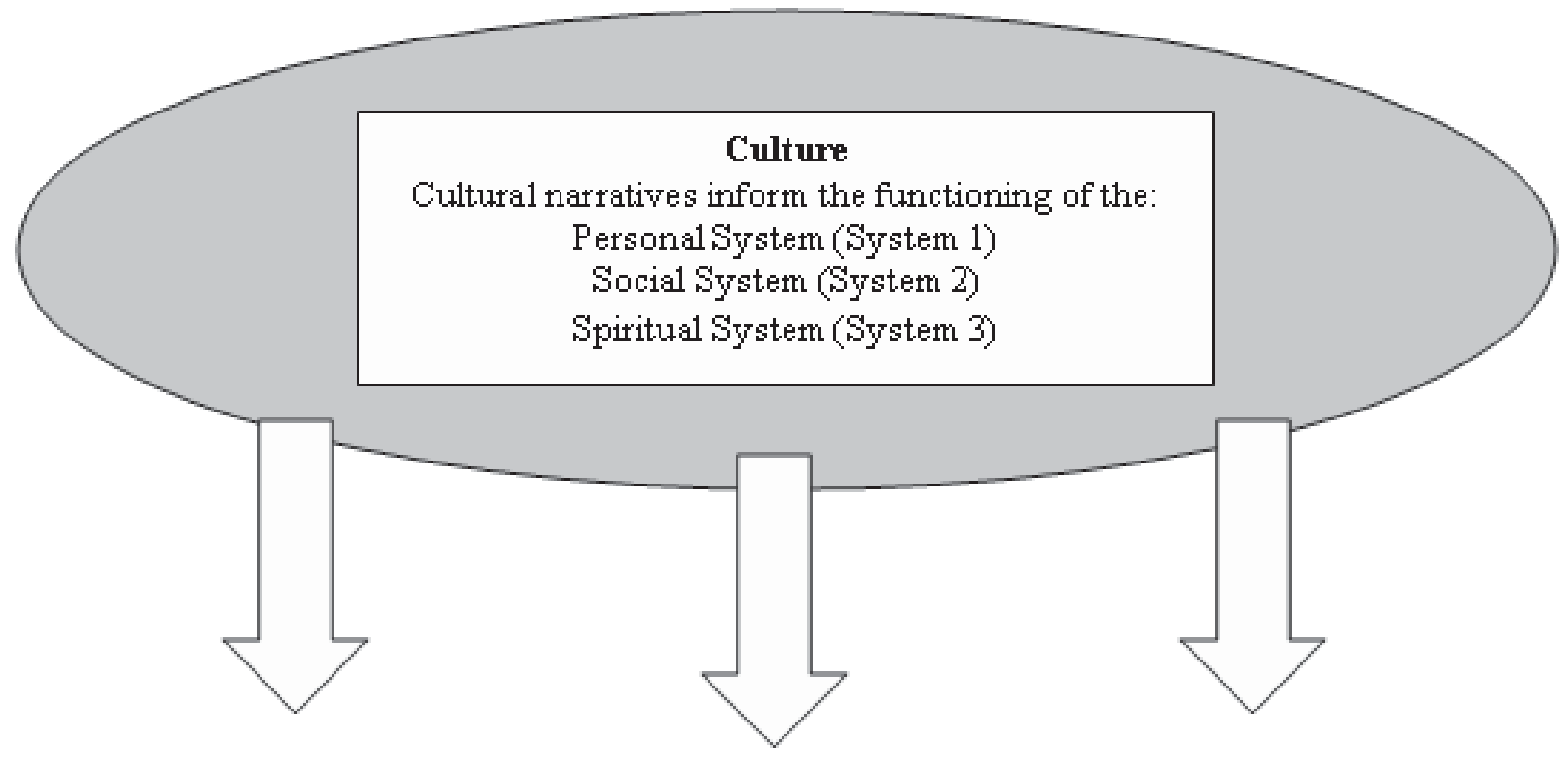

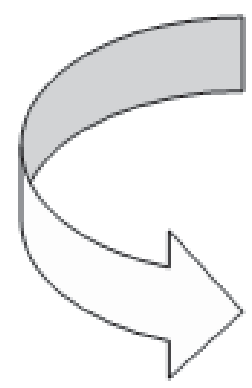

System 1

Personal Syste m

Relationship with 'Self", and its impact on sport participation and performance

\section{System 3}

Spiritual System

Relationship with a

'Deity', and its impact on sport participation and performance

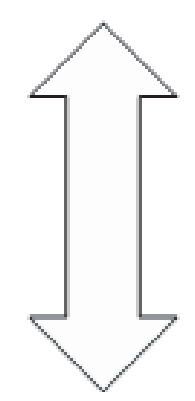

\section{Athlete}

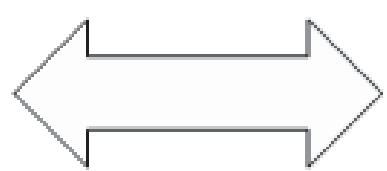

System 2

Interpersonal Syste m

Relationship with 'Others', and its impact on sport participation and performance 
of athletes' lives as well the influence the spiritual systems has on an athlete's participation and performance in sport.

The existence and functioning of these interrelated systems do not occur in a vacuum, but are imbedded in culture. According to Cushman (1995, p.17-18):

Culture is not indigenous 'clothing' that covers the universal human; rather it is an integral part of each individual's psychological flesh and bones ... the material objects we create, the ideas we hold and the actions we take are shaped in a fundamental way by the social framework we have been raised in.

Culture is not mechanistic and static but is organic and flexible, continuously changing over time and varies greatly from place to place (Cromby \& Nightingale, 1999). It has to do with the basic assumptions of a community, which influences the thoughts, feelings and behaviour of that community and which manifest in, for example, rituals, symbols and processes (Weisner \& Millet, 2000). Furthermore, culture creates a community identity that distinguishes one community from another and it contributes to the construction of the identity of the members of a community. It also guides the members of a community concerning acceptable and unacceptable behaviour within a specific community (Werner, 2003).

One of the most important aspects of culture is cultural narratives, also referred to as cultural discourses. Cultural narratives are "regimes of truth" (Lowe, 1991, p. 43) and are seen as a "public process of conversation" and/or "systematic and institutionalised ways of speaking/writing" (Lowe, 1991, p. 45). Parker (1992, p. 245) describes cultural narratives as "sets of statements that construct objects and an array of subject positions". These cultural narratives are created and sustained by all societies and heavily influenced by powerful media like music, newspaper, television and the film industry (Monk, Winslade, Crocket \& Epston, 1997). Cultural narratives are found all around us, for example, there are cultural narratives on abuse, doping, gender and racism (Swain, 2000), which afford athletes ways-of-being. They dictate how an athlete's personal system, social system and spiritual system "should" be (Willig, 2001). It is important to note that there are dominant cultural narratives and alternative cultural narratives in circulation in society. The dominant cultural narratives and alternative cultural narratives oppose one another, but also sustain one another. For example, in SA a dominant cultural narrative exists that "rugby is for men and netball is for women". However, female rugby is also played in SA, which introduces an alternative cultural narrative of "rugby is for women". The dominant cultural narrative of rugby is for men and netball is for women and the alternative cultural narrative of rugby is for women oppose one another and can often lead to women who play rugby to be marginalized by those in society who support the dominant cultural narrative of rugby is for men and netball is for women. This is often done through limited television exposure and financial support.

Cultural narratives are not descriptive and passive but are active, constructed and constructive (Coyle, 2000) and consequently have a dual nature. On the one hand, they are constructed by society and, on the other hand they construct society. They are, therefore, constructed and constructive. An analogy in the world of sport is a game of squash. In a sport like squash, players, coaches, umpires and administrators get together and construct the rules that should govern a squash game. Through this social process, squash rules are con- structed. In the playing of a game of squash by squash players the rules become constructive in that they dictate how the game should be played. Cultural narratives can be seen as language in action as, on the one hand, cultural narratives are constructed by society while on the other hand, they afford people ways-of-being. They afford people positions and/or subjectivities and they dictate how people should think, feel and act in relation to themselves and to other people in a given situation (Willig, 2001).

Within any given cultural context there are dominant and alternative cultural narratives regarding a specific phenomenon and it is these cultural narratives that have a shaping effect on athletes' personal, social and spiritual systems (Redwood, 1999). Cultural narratives prescribe certain ways-of-being in the world of which there can be dominant and alternative ways-of-being. Cultural narratives prescribe subject positions which, when taken up, have implications for subjectivity and experience. Our identities, our ways-of-being are the achievement of discourse (narratives) rather than cognition (Gergen, 1994). For example, from within the biomedical discourse, those who experience ill health occupy the subject position of patient, which locates them as the passive recipient of expert care within a trajectory of cure (Willig, 2001).

To elaborate on the analogy of squash. The game of squash can be played as a singles-game or as a doubles-game, which are completely different. The rules are different, the communication on the court is different, the scoring is different and the way you move on the court is different. The cultural narratives informing singles-squash and doubles-squash are very different and afford a squash player different ways-of-being when he/she is playing singles-squash versus doubles-squash.

It seems that employing multiple perspectives is a desirable practice guideline for counsellors, as no one perspective allows a counsellor to understand athletes in their totality. It is therefore recommended that a counsellor working with athletes is proficient in viewing athlete behaviour from multiple perspectives.

\section{Guideline 3: Counsellor Services}

The third practice guideline for counsellors working with athletes is integrated counsellor services. A counsellor can render psychological assessment, sports counselling, sport psychology and report writing according to the MCS-SP, a model for the comprehensive evaluation, conceptualization, and treatment of the athlete population (Gardner \& Moore, 2004).

\section{Psychological Assessment}

Psychological assessment is a service that counsellors render to athletes (Ward et al., 2005). A MCS-SP is proposed to compliment classification systems mainly used in medicine and psychology, such as the DSM and the ICD. The MCS-SP can be used by counsellors in delivering psychological assessment to athletes. The MCS-SP has the following levels (Gardner \& Moore, 2004):

Performance Termination (PT)(Level 1). The focus is on the termination of an athlete's sport career due to various reasons with no possibility for re-instituting an athlete's sport career. Sports counselling is the preferred intervention for performance termination work.

Performance Impairment (PI)(Level 2). The focus is on mental disorders, as well as other limitations placed on an athlete's sport career that impairs an athlete's performance. Sports 
counselling is the preferred intervention for performance impairment work.

Performance Dysfunction (PDy)(Level 3). The focus is on psycho-social problems that are present in an athlete's life and are clearly impacting negatively on the performance of the athlete. Sports counselling is the preferred intervention for performance dysfunction work.

Performance Development (PD)(Level 4). The focus is on performance enhancement in the absence of psycho-social problems that might negatively influence the performance of the athlete. Sport psychology is the preferred intervention for performance enhancement work.

The three most prominent psychological assessment activities that are used by counsellors are usually observation, interviewing and psychometry (Gardner \& Moore, 2004).

\section{Sports Counselling}

Besides a psychological assessment service, sports counselling is another service a counsellor can render to athletes (Cole \& Tinsley, 2009; Hays, 1995). Sports counselling is described as the psychological process that unfolds between a counsellor and athletes, with the aim of addressing problems pertaining to performance termination (Level I: MCS-SP), performance impairment (Level II: MCS-SP) and performance dysfunction (Level III: MCS-SP)(Gardner \& Moore, 2004). Additionally, sports counselling is concerned with the developmental needs of the athlete population including personal and clinical issues as well as concerned with the psycho-social needs and difficulties of athletes.

\section{Sport Psychology}

Alongside psychological assessment and sports counselling services, a counsellor can also deliver a sport psychology service to athletes. Sport psychology is described as the psychological process that unfolds between a counsellor and athletes, with the aim of addressing performance development (Level IV: MCS-SP)(Gardner \& Moore, 2004). Hays (1995) states that sport psychology is often equated with performance development.

Traditionally, the delivery of a sport psychology service, which primarily focuses on performance development, is done via a psycho-educational process (Halliwell, 1990), also known as Psychological Skills Training (PST)(Tenenbaum, Papaianou \& Samulski, 2002), and is predominantly based on cognitive-behaviour psychology (Gardner, 2001). The underlying principle of PST is that certain "thoughts and feelings can inhibit optimal performance and likewise that certain mental skills, used effectively, can enhance optimal performance" (Hays, 1995, p. 35).

An alternative approach, to the PST-approach regarding performance development (Level IV: MCS-SP), is emerging on the horizon of sport psychology. This approach is known as the Mindfulness-Acceptance-Commitment (MAC) approach. Mindfulness refers to the process in which a counsellor assists athletes to develop an awareness of all their experiences, irrespective of these experiences being labelled as positive or negative by athletes. Acceptance entails the process whereby athletes are able to accept all their experiences as natural and normal, while maintaining the ability to focus on the task at hand despite these experiences. Commitment is the ability of athletes to consistently and continuously engage in behaviour that have a high probability for creating optimal performance, despite the array of experiences athlete might experience (Gardner \& Moore, 2006; 2007).

\section{Report Writing}

A counsellor working with athletes can also be required to write reports about those athletes based upon the psychological assessment, sports counselling and sport psychology services. On the one hand, these reports can be directed to other professionals while on the other hand reports can also be directed to the coach. Considerable care needs to be taken not to divulge unnecessary information to other professionals and/or coaches as this might influence the relationship between a counsellor and athletes. Reports should be specific in that they only convey relevant information to other professionals and/or coaches, and a counsellor should always involve athletes in the reports that they are writing for other professionals and/or coaches.

It seems that the practice guideline of delivering integrated counsellor services to athletes, in the form of psychological assessment, sports counselling, sport psychology and report writing, can enhance the sporting experience of athletes.

\section{Guideline 4: Counsellor Ethics}

The fourth practice guideline for counsellors working with athletes is the ethical stance of the counsellor. Besides taking cognizance of the legal framework of the various countries within which counsellors' practice, the ethical aspects of referrals, privacy and cultural sensitivity need special attention.

\section{Referrals}

Counsellors should not be afraid to refer athletes to other counsellors or other professionals, if they do not have the adequate counselling training, competence or necessary experience to assist athletes (Allen, 2001).

\section{Privacy}

On the one hand, the right to privacy pertains to the "right against intrusion", which entails that athletes have a right to keep certain information about themselves private from counsellors and are not obliged to reveal everything about themselves to counsellors. One the other hand, the right to privacy focuses on the "right to confidentiality", which refers to the right of athletes to maintain control over the information that they have shared with counsellors. There are certain instances where the right to privacy can be waived. These are consent, emergencies, necessity, a court order, as well as statutory requirements (Allen, 2001).

\section{Cultural Sensitivity}

Culturally sensitive counsellors are aware of their own cultural values and biases, as well as those of their clients' (American Counselling Association, 2005). Simons and Andersen (1995) say that the most important part of being a counsellor is to "Know Thyself", as Socrates said 2500 years ago. George and Christiani (1990, p. 12) state:

Before we can focus on what happens to the client involved in the counselling process, we should consider the other person involved in the therapeutic intervention - the counsellor. In their professional behaviour, counsellors draw on three somewhat different areas: personal qualities, professional knowledge, and specific counselling skills. Thus, the qualities of the counsellor as a person, as opposed to what he or she actually does during counselling, require special attention.

Upholding high ethical standards is a practice guideline that should be an integral part of all counsellors, irrespective if they work with athletes. Not only do people who seek the assistance of counsellors have the right to be treated ethically, but it com- 
municates a basic respect to those who seek the assistance of counsellors.

\section{Guideline 5: Counsellor Research}

The fifth practice guideline for counsellors working with athletes is counsellor research. In this section of the article three aspects regarding research are addressed. Firstly, research endeavours in sports counselling receive attention. Secondly, research endeavours in sport psychology are described. Lastly, research horizons are addressed in which possibilities for future research are explored.

\section{Sports Counselling Research}

Research on sports counselling is something that is developing in Africa. Due to the lack of sports counselling research in other-than-Westernised countries, it becomes difficult to generalize the findings from the USA and other Westernised countries to that of African countries (Malete, 2000). Due to the HIV/AIDS pandemic throughout the continent of Africa, the greatest focus of research in many African countries, and the most extensive, currently is on HIV/AIDS. Many projects and programs on this issue are very well funded and to some extent have received thorough marketing, promotion and publicity (Moeti, 2000). The challenges are that behaviour change is very slow, while people die every second because of this issue (Samba, 2000). Athletes are not spared the condition since they are part of communities struggling with HIV/AIDS. "Within the HIV/AIDS sector, there is a growing recognition that Sport for Development (SfD) [and sports counselling] approaches can achieve significant HIV prevention goals ... [and has] potential to develop effective youth HIV/AIDS programs" (Mercy Report, 2007). However, the authors of this chapter do not suggest that sports counselling interventions and services in Africa be solely based on the research conducted in the USA and other Westernised countries. "A meaningful transformation of sport in [Africa] does not lie in a wholesale copying of some nation's sports policy documents and religiously applying them to our [Africa's] situation" (Malete, 2000, p. 36). Programs have been developed or culturally modified in Africa that promote psycho-social development, enhance health and wellness, while promoting abstinence among the youth by encouraging sport participation. Two programs are highlighted in this chapter.

Firstly, the Norwegian Olympic Committee and the Confederation of Sports (NIF) collaborated with countries in Southern Africa, to develop the Kicking AIDS Out! network, which is an international network of organisations working together to use sport and physical activity as a means to raise awareness of HIV/AIDS and motivating behavioural change among the youth. Although some countries are successful in running the Kicking AIDS Out! program, limitations still exist. The program utilizes teachers or coaches trained in physical education as well as trained in several aspects of HIV/AIDS (Kicking AIDS Out!, 2008). Additionally, the program employs the concept of peer leadership in their approach towards the youth who range in age from 13 to 19 (Jakobsen, 2004). However, based on the program's research and limitations, the program may want to consider including professionally trained counsellors, who, after the Kicking AIDS Out! sport activities, could address issues and concerns related to HIV/AIDS raised by young people in an ethical manner. "Leaders who work with Kicking AIDS Out! need to know their community well; they need to know what services exist like support groups, HIV testing facilities and clinics and counselling services" (Jakobsen, 2004, p. 11).
Secondly, Grassroots Soccer (GRS) is an example of another culturally sensitive program that encourages pro-social skills through sports for the youth and young adults aged 15-24. GSR uses soccer, an HIV prevention education curriculum and a life-skills curriculum to provide the African youth with the knowledge, skills, and support to live HIV free. GSR utilizes scientific based research and evaluation to extensively assess the effectiveness of the program. The evaluation findings indicate that the GRS HIV/AIDS Education Program significantly improves student knowledge, attitudes, and perceptions of social support related to HIV/AIDS (Grassroots Soccer, 2008). This program also utilizes teachers, coaches and peer educators as mentors and could benefit from the services of professional counsellors.

When counselling athletes of African ancestry in a sport context, ethical practice requires that professionals provide counselling interventions and services within the realm of their training and competence. Based on scientific research, both the Kicking AIDS Out! and the GRS programs could benefit from the expertise and competence of professionally trained counsellors who could provide ethical and effective interventions and services to athletes.

\section{Sport Psychology Research}

According to Biddle, Markland, Gilbourne, Chatzisarantis and Sparkes (2001), as well as Singer and Burke (2002), research within the field of sport psychology has traditionally been done from a quantitative research approach, more specifically within the framework of cognitive psychology and that it has often been laboratory-centered and experimental in nature.

It seems that the major sport psychology journals, such as the JASP, TSP, IJSP and JSEP, tend to publish research done from a quantitative approach, although these journals recently seemed more open to research done from a qualitative approach. Schutz and Gessaroli (1993) indicate that there have been calls for greater methodological diversity within the world of sport psychology, Strean and Roberts (1992) have called for the greater use of qualitative methods, while Sparkers (1998) and Strean (1998) indicate that more attention be placed on raising awareness regarding the diversity of qualitative research methods. Morris (in Biddle et al., 2001) analysed the publication trends in the JSEP between 1979 and 1998 and found, for example that only $1,3 \%$ of papers published in the JSEP were qualitative in nature, while $15,5 \%$ of the papers published in this journal had a strong psychometric content. Biddle (1997) did a similar study and also analysed the publication trends in the JSEP and the IJSP between 1985 and 1994 and found that only $6 \%$ of the articles in these two journals were qualitative in nature. Culver, Gilbert, Trudel (2003) researched the distribution of quantitative and qualitative articles published in the JASP, the JSEP and TSP between 1990 and 1999. They found that of the 485 articles published in these journals during this time, 401 (83\%) were quantitative and 84 (17\%) were qualitative in nature.

As already mentioned, Singer and Burke (2002) also indicate that qualitative research approaches are slowly but surely penetrating the world of sport psychology. The research that is done from this position is not guided by cognitive psychology but by social psychology, it is not done in a laboratory but in the field, it is not experimental in nature but tries to understand behaviour within everyday sport settings and has as its aim the development of practical knowledge, which will primarily serve the athlete. In this regard Hall (1996, p. 78) states that "what goes 
on in academia, at least as far as feminism is concerned, should be directed to producing the kind of knowledge wanted and needed by those outside academia who are working for social change".

\section{Future Sports Counselling and Sport Psychology Research}

On the one hand future research in Africa can focus on the development and strengthening of training programs for counsellors who wish to work with athletes, while on the other hand it can be directed by the services that need to be delivered to athletes.

Firstly, research can focus its attention on the standardization of these psychological assessment instruments, or even the development of Africa-based psychological assessment instruments. Secondly, research can pay attention to the domain of sports counselling. Research can focus on the area of sports counselling with specific reference to performance termination (Level I: MCS-SP), performance impairment (Level II: MCS-SP) and performance dysfunction (Level III: MCS-SP. Lastly, research can focus on the area of sport psychology with specific reference to performance development (Level IV: MCS-SP), which can either be done according to the PST-approach or the MAC-approach.

The practice guideline of counsellor research is often a neglected one, as not all counsellors engage actively in research. However, all counsellors should take up the responsibility to contribute to research and should also be held accountable that research informs practice and that practice informs research.

\section{Conclusion}

In this article the focus was on proposing practice guidelines for counsellors working with athletes. The first practice guideline emphasized the importance of counsellor training as depicted in the history of sports counselling and sport psychology. The second practice guideline focussed on various perspectives that counsellors can employ when working with athletes, and avoid the approach that athletes' behaviour can be understood through only one perspective. The third practice guideline proposed an integrated service delivery to athletes in a sport context, of which psychological assessment, sports counselling, sport psychology and report writing were addressed in this article. Ethical aspects, such as referrals, privacy and cultural sensitivity were discussed as the fourth practice guideline, while research endeavours as the fifth practice guideline focused on research in the past and possible research areas for the future.

The departure point set out at the beginning of this article was that sport should not just be about winning or losing, but should also allow athletes to become better people, to strive for excellence. In the words of Paterno (in Lesyk, 2001, p. 7), "excellence is something that's lasting, dependable, and largely within a person's control." To achieve this, this article has set forth guidelines for counsellors to assist athletes to obtain personal development through sport and achieve enhanced performance in their chosen sport. Furthermore, the article aims at equipping counsellors to direct athletes to strive for excellence in their chosen sport, and to transfer this excellence into other areas of their lives, so that sport can help create people who strive for excellence on the continent of Africa, and help make Africa an excellent continent and not necessarily a successfu continent.

\section{References}

Abernethy, B., Bond, J., Glencross, D.J., Grove, J.R., \& Salmela, J. (1992). Australia. In J. Salmela (Ed.), World sport psychology sourcebook (2nd ed., pp. 8-14). Champaign: Human Kinetics.

Allan, A. (2001). The law for psychotherapists and counsellors. South Africa: Inter-Ed.

American Counseling Association. (2005). Cross-cultural competencies and objectives. Retrieved January 13, 2008, from http://www.counseling.org

American Psychiatric Association (APA). (2007). Diagnostic and statistical manual for mental disorders (4th ed.). Retrieved September 10, 2007, from http://www.psychiatryonline.com

Anderson, M.B., Van Raalte, J.L., \& Brewer, B.W. (2001). Sport psychology service delivery: Staying ethical while keeping loose. Professional Psychology: Research and Practice, 32, 12-18.

Barlow, D.H., \& Durand, V.M. (1995). Abnormal behavior. An integrative approach. New York: Brooks/Cole.

Biddle, S.J.H. (1997). Current trends in sport and exercise psychology research. The Psychologist: Bulletin of the British Psychological Society, 10, 63-69.

Biddle, S.J.H., Markland, D., Gilbourne, D., Chatzisarantis, N.L.D., \& Sparkes, A.C. (2001). Research methods in sport and exercise psychology: Quantitative and qualitative issues. Journal of Sport Sciences, 19, 777-809.

Brewer, B.W., \& Van Raalte, R.L. (2002). Introduction to sport and exercise psychology. In J.L. van Raalte \& B.W. Brewer (Eds.), Exploring sport and exercise psychology (2nd ed., pp. 3-9). Washington, DC: American Psychological Association.

Brown, R.C. (Jr.). (1978). The "jock trap". How the black athlete gets caught. In W.F. Straub (Ed.), Sport psychology: An analysis of athlete behavior (pp. 195-198). Ithaca, NY: Movement.

Cole, K. W., \& Tinsley, T. M. (2009). Sports counseling. In American Counseling Association (Ed.), The ACA encyclopedia of counseling (pp. 522-524). Alexandria, VA: ACA.

Corey, G. (2001). Theory and practice of counseling and psychotherapy (6th ed.). Belmont, KY: Wadsworth.

Coyle, A. (2000). Discourse analysis. In G.M. Breakwell, S. Hammond \& C. Fife-Schaw (Eds.), Research methods in psychology (2nd ed., pp. 251-268). London, England: Sage.

Cromby, J., \& Nightingale, D.J. (1999). What's wrong with social constructionism? In D.J. Nightingale \& J. Cromby (Eds.), Social constructionist psychology. A critical analysis of theory and practice (pp. 1-19). Buckingham, England: Open University Press.

Culver, D.M., Gilbert, W.D., \& Trudel, P. (2003). A decade of qualitative research in sport psychology journals. The Sport Psychologist, 17, 1-15.

Cushman, P. (1995). Constructing the self, constructing America: A cultural history of psychotherapy. Reading, PA: Addison-Wesley.

Davis, S.F., Huss, M.T., \& Becker, A.H. (1995). Norman Triplett and the dawning of sport psychology. The Sport Psychologist, 9, 366-375.

Gardner, F.L. (2001). Applied sport psychology in professional sports: The team psychologist. Professional Psychology: Research and Practice, 32, 34-39. 
Gardner, F.L., \& Moore, Z.E. (2004). The multi-level classification system for sport psychology (MCS-SP). The Sport Psychologist, 18, 89-109.

Gardner, F.L., \& Moore, Z.E. (2006). Clinical sport psychology. Champaign: Human Kinetics.

Gardner, F.L., \& Moore, Z.E. (2007). The psychology of enhancing human performance. The mindfulness-acceptance-commitment (MAC) approach. New York: Springer.

Gergen, K.J. (1994). Realities and relationships: Soundings in social construction. London, England: Harvard University Press.

George, R.L., \& Christiani, T.S. (1990). Counselling. Theory and practice. (3rd ed.). Englewood Cliffs: Prentice-Hall.

Gould, D., \& Pick, S. (1995). Sport psychology: The Griffith era, 1920-1940. The Sport Psychologist, 9, 391-405.

Grassroots Soccer. (2008). About grassroots soccer. Retrieved June 9, 2008, from http://www.GrassrootSoccer.org.

Hall, M.A. (1996). Feminism and sporting bodies: Essays on theories and practice. Champaign, IL: Human Kinetics.

Halliwell, W. (1990). Providing sport psychology consulting services in professional hockey. The Sport Psychologist, 4, 369-377.

Hays, K.F. (1995). Putting sport psychology into (your) practice. Professional Psychology: Research and Practice, 26, 33-40.

Johnson, C., Powers, P.S., \& Dick, R.W. (1999). Athletes and disorders. The national collegiate athletic association study. International Journal of Eating Disorders, 26, 179-188.

Jakobsen, E. (2004). Kicking AIDS Out! Using sport as a tool in the fight against HIV/AIDS. Retrieved June 9, 2008, from http://www.kickingaidsout.net

Kicking AIDS Out! (2008). What is Kicking AIDS Out! Retrieved June 9, 2008, from http://www.kickingaidsout.net

Lesyk, J.J. (2001). Quotation collection. The nine mental skills of successful athletes. Beachwood, $\mathrm{OH}$ : Ohio Center for Sport Psychology.

Lowe, R. (1991). Postmodern scenes and therapeutic practices: Notes towards the definition of "Family Therapy: Part 2". Dulwich Centre Newsletter, 3, 41-52.

Long-Term Athlete Development (LTAD). (2006). Canadian Sport for Life. Retrieved September 8, 2006, from http://www.cd.gov.ab.ca

Mahoney, M.J., \& Suinn, R.M. (1986). History and overview of modern sport psychology. The Clinical Psychologist, Summer, 64-68.

Malete, L. (2000). Psychological correlates of sport and leisure physical activity participation among Botswana youths. Dissertation abstracts international: Section B: The sciences \& engineering 61(8-B). (UMI No. 9985426).

Marchant, D., \& Gibbs, P. (2004). Ethical considerations in treating borderline personality disorder in sport: A case example. The Sport Psychologist, 18, 317-323.

May, J.R. (1986). Sport psychology: Should psychologists become involved? The Clinical Psychologist, 39, 77-81.

Mercy Report. (2007). Commitment to practice: A playbook for practitioners in HIV, youth and sport. Retrieved June 9, 2008, from http://www.grassrootsoccer.org.

Meyer, W.F., \& Van Ede, D.M. (1994). Ontwikkelingsteorieë. In D.A Louw (Red.), Menslike ontwikkeling (2de Uitgawe, pp. 51-102). Pretoria: Haum.
Moeti, M. (2000, July-December). International partnership against HIV/AIDS in Africa: What it is and how it works. African Health Monitor, 1, 6-7.

Monk, G., Winslade, J., Crocket, K., \& Epston, D. (1997). Narrative therapy in practice: The archaeology of hope. San Francisco: Jossey-Bass.

Morgan, W.P. (1985). Selected psychological factors limiting performance: A mental health model. In D.H. Clarke \& H.M. Eckert (Eds.), Limits of human performance (pp. 70-80). Champaign: Human Kinetics.

Morris, T. (1995). Sport psychology in Australia: A professional establishment. Australian Psychologist, 30, 128-134.

Murphy, S.M. (1995). Introduction to sport psychology interventions. In S.M. Murphy (Ed.), Sport psychology interventions (pp. 1-15). Champaign: Human Kinetics.

Nejedlo, R. J., Arrendondo, P., \& Benjamin, L. (1985). Imagine: $A$ visionary model for the counselors of tomorrow. DeKalb, $\mathrm{RI}$ : George's Printing.

Parker, I. (1992). Discourse dynamics: Critical analysis for social and individual psychology. London, England: Routledge.

Pillari, V (1988). Human development in the social environment. Pacific Grove, CA: Brooks/Cole.

Potgieter, J.S. (1997). Sport psychology. Theory and practice. University of Stellenbosch, South Africa: Institute for Sport and Movement Studies.

Preller, A.C.N. (1989). Eksistensieël-fenomenologiese perspektiewe van abnormale gedrag. In D.A. Louw (Red.), Suid-Afrikaanse handboek van abnormale gedrag (pp. 95-107). Johannesburg, South Africa: Southern Boekuitgewers.

Redwood, R. (1999). Caring control: Methodological issues in a discourse analysis of waterbirth texts. Journal of Advanced Nursing, 29, 914-921.

Samba, E. M. (2000, July-December). From the regional director's desk. African Health Monitor, 1, 1.

Schutz, R.W., \& Gessaroli, M.E. (1993). Use, misuse and disuse of psychometrics in sport psychology research. In R.N. Singer, M. Murphy \& L.K. Tennant (Eds.), Handbook of research in sport psychology (pp. 901-917). New York: Macmillan.

Sherman, R.T., \& Thompson, R.A. (2001). Athletes and disordered eating: Four major issues for the professional psychologist. Professional Psychology: Research and Practice, 32, 27-33.

Simons, J.P., \& Andersen, M.B. (1995). The development of consulting practice in applied sport psychology: Some personal perspectives. The Sport Psychologist, 9, 449-468.

Singer, R.N., \& Burke, K.L. (2002). Sport and exercise psychology: A positive force in the new millennium. In J.L. van Raalte \& B.W. Brewer (Eds.), Exploring sport and exercise psychology (2nd ed., pp. 525-537). Washington, DC: American Psychological Association.

Sparkes, A.C. (1998). Validity in qualitative inquiry and the problem of criteria: Implications for sport psychology. The Sport Psychologist, 12, 363-383.

Stellenbosch University (SUN). (2002a). Academic programmes: Postgraduate. Retrieved April 1, 2003, from http://www.sun.ac.za

Stellenbosch University (SUN). (2002b). Sport science: Staff. Retrieved April 1, 2003, from http://www.sun.ac.za. 
Strean, W.B. (1998). Possibilities for qualitative research in sport psychology. The Sport Psychologist, 12, 333-345.

Strean, W.B., \& Roberts, G.C. (1992). Future directions in applied sport psychology research. The Sport Psychologist, 6, 55-65.

Sundgot-Borgen, J. (1994). Risk and trigger factors for the development of eating disorders in female elite athlete. Medicine and Science in Sports and Exercise, 26, 414-419.

Swain, J. (2000). The moneys good, the fame's good, the girls are good: The role of playground football in the construction of young boys' masculinity in junior school. British Journal of Sociology of Education, 21, 95-110.

Tenenbaum, G., Papaianou, A., \& Samulski, D. (2002). Competencies (occupational standards, knowledge and practice) and their accomplishments (learning specification; essential knowledge and skills) in sport and exercise psychology: An ISSP position stand. Unpublished manuscript.

Theron, A., \& Louw, D.A. (1989). Die geskiedenis, aard en klassifikasie van abnormale gedrag. In D.A. Louw (Red.), Suid-Afrikaanse handboek van abnormale gedrag [South African texbook for abnormal behavior] (pp. 3-37). Johannesburg, South Africa: Southern Boekuitgewers.

Tinsley, T. M., \& Levers, L. L. (2007). Fostering self-determination and resilience through sports counseling: Psychosocial development of youth in Botswana. Journal of Psychology in Africa, 17, 23-32.

Tricket, E.J., Watts, R.J., \& Birman, D. (Eds.) (1994). Human diversity: Perspectives on people in context. San Francisco: Jossey-Bass.

Ward, D.G., Sandstedt, S.D., Cox, R.H., \& Beck, N.C. (2005). Athlete-counseling competencies for U.S. psychologists working with athletes. The Sport Psychologist, 19, 318-334.

Weisner, R., \& Millet, B. (2001). Management and organisational behaviour. Richmond, Australia: Wiley.

Werner, A. (2003). Organisational culture, ethics and diversity in a global environment. In $\mathrm{H}$. Schultz (Ed.), Organisational behaviour. A contemporary South African perspective (pp. 22-36). Pretoria, South Africa: Van Schaik.

White, M. (2000). Reflections on narrative practice. Essays \& interviews. Adelaide, Australia: Dulwich Centre.

Willig, C. (2001). Introducing qualitative research in psychology. Adventures in theory and method. Buckingham, England: Open University Press.

World Health Organization (WHO). (2007). History of the development of the ICD. Retrieved September 10, 2007, from http://www.who.int

Wright, J.H., Basco, M.R., \& Thase, M.E. (2006). Learning cognitive-behaviour therapy: An illustrated guide. Washington, DC: American Psychiatric Publishing.

\section{Endnotes}

${ }^{1}$ For the purpose of this article, a "counsellor" is a person who engages in a professional relationship with athletes with the purpose of assisting athletes in enabling their own resources with the aim of becoming better people through sport. In this article a "counsellor" can refer to, for example, educators, psychologists, professional counselors, social workers and/or sport scientists involved with athletes of African ancestry in a sport context.

${ }^{2}$ In the remainder of this chapter the term "athlete(s)" is used to refer to "athlete(s) of African ancestry in a sport context" 